\title{
Desmentindo as falsas comparações: do corpo perceptivo ao corpo fantasmático
}

\author{
Refuting the false comparisons: \\ from the perceptive body to the \\ phantasmatic body
}

\section{Thamy Ayouch}

Professor de Psicopatologia Clínica e Filosofia na Université Charles de Gaulle - Lille 3, psicanalista, psicólogo clínico, Lille, França, e-mail: thamy.ayouch@gmail.com

\section{Resumo}

As verdadeiras comparações precisam, primeiro, ressaltar o que opõe os comparados. A partir das suas respectivas relações à atestação, definições epistemológicas e vínculos com uma clínica, a psicanálise e a fenomenologia parecem opostas de vários modos. Porém, Merleau-Ponty as aproxima, nas suas conceituações do corpo vivido e do afeto. Todavia, as duas disciplinas se revelam muito díspares com respeito ao corpo perceptivo, secundário para a psicanálise, que teoriza sobre um corpo imaginário primário. Gostaria de examinar aqui as similitudes e divergências entre o corpo fenomenológico merleau-pontyano e o corpo fantasmático freudiano. Se a psicanálise reverte, nas suas teorizações, as categorias fenomenológicas 
de percepção e imaginação, a fenomenologia permite, entretanto, resolver algumas aporias metafísicas da psicanálise.

Palavras-chave: Corpo próprio. Fantasma. Merleau-Ponty. Psicanálise. Fenomenologia.

\begin{abstract}
Genuine comparisons need highlighting first what really opposes the compared. Through their respective relation to what can be attested or not, their epistemological definition and their link to practice, psychoanalysis and phenomenology seem opposed in many ways. However, Merleau-Ponty tends to draw them together, insofar as they both set forth the priority of a subjective lived body, linked to the affect. Nevertheless, their perspectives seem to differ when it comes to the primacy of the perceptive body, which psychoanalysis deems as secondary, and lying on a primary imaginary body. This paper examines the similarities and discrepancies between the Merleau-Pontyan phenomenological body and the Freudian fantasmatic body. It attempts to show how the categories of perception and imagination are reversed when moving from phenomenology to psychoanalysis, and yet how the former may help go beyond certain metaphysical aporiae presented by the latter.
\end{abstract}

Keywords: Proper body. Ghost. Merleau-Ponty. Psychoanalysis. Phenomenology.

\title{
Introdução
}

My mistress' eyes are nothing like the sun;

Coral is far more red than her lip's red; If snow be white, why then her breasts are dun ${ }^{1}$

1 "Os olhos da minha amada não são nada como o sol

São vermelhos os seus lábios, mas o coral é mais rubro

Se a neve é branca, são morenos os seus seios"

(SHAKESPEARE, 1994). Tradução livre do autor. 
Assim começa o soneto 130 de Shakespeare, cujo processo retórico consiste em desmentir todas as comparações mentirosas da poesia de amor. Portanto, as bochechas da dama não têm nada a ver com as rosas de Damasco, os perfumes finos são muito mais deleitosos do que o seu hálito, e a música é incontestavelmente mais agradável do que a sua voz. Todavia, o poema termina restaurando a comparação, num duplo sentido:

\section{And yet, by heaven, I think my love as rare As any she belied with false compare}

Porém, pelo céu, encontro o meu amor tão raro Como qualquer outro cujas comparações ela desmente

$\mathrm{Ou}$

Porém, pelo céu, encontro na minha amada tanta graça Como em todas aquelas que as falsas comparações enganaram.

Portanto, só desmanchando falsas comparações pode-se chegar à verdade de uma comparação final, aproximando o que foi separado ao longo do poema: o amor do poeta e o amor da poesia galante, a verdade e a lisonja, a graça da dama e a das donas celebradas pela poesia cortês. Assim, gostaria de tentar engajar-me num desmentido das aproximações habituais entre psicanálise e fenomenologia: é preciso, em primeiro lugar, realçar o que as separa para poder melhor atinar sobre o que as une. Os campos de comparação são múltiplos e escolheria um aspeto particular: a questão do corpo.

My mistress eyes are nothing like the sun. No prefácio de A. Hesnard L'Euvre et l'esprit de Freud, Maurice Merleau-Ponty considera, em 1960, que a fenomenologia está "mais que sempre em convergência com a pesquisa freudiana” (MERLEAU-PONTY, 2000, p. 281). No entanto, é pelo menos surpreendente que duas disciplinas opostas nas suas definições habituais sejam consideradas como convergentes. Uma centra a sua pesquisa no inconsciente, a outra na consciência; a primeira prefere as tendências supostas embaixo dos fenômenos percebidos, a outra se limita a uma descrição mais fiel da percepção; uma tem referências de biologia e termodinâmica tanto como de interpretação e sentido, enquanto a outra, que radicaliza a diferença diltheyana entre ciências da natureza e ciências do espírito, posiciona-se explicitamente do lado das segundas.

Se referirmo-nos à definição da psicanálise por Freud (1923, p. 51), vemos que o termo indica três áreas ligadas: 
PSICANÁLISE é o nome de (1) um procedimento para a investigação de processos mentais que são quase inacessíveis por qualquer outro modo, (2) um método (baseado nessa investigação) para o tratamento de distúrbios neuróticos e (3) uma coleção de informações psicológicas obtidas ao longo dessas linhas, e que gradualmente se acumula numa nova disciplina científica. ${ }^{2}$

Nessa definição de um objeto inacessível diretamente, fusionando a abordagem, o método do tratamento e o tipo de cientificidade, jaz a dificuldade de qualquer aproximação entre fenomenologia e psicanálise, e o desmentido de toda falsa comparação. Três níveis problemáticos são aqui convocados:

- o problema da atestação: a fenomenologia é somente descritiva: empenha-se em descrever o que aparece para a consciência. A psicanálise é construtiva: edifica-se em torno do postulado fundamental do inconsciente, termo que se refere àquilo que nunca aparece diretamente, mas unicamente através dos seus efeitos.

- o problema do marco epistemológico: vários fenomenólogos - Husserl, Heidegger, Binswanger, Boss, etc. - reprovaram a dimensão quantitativa reducionista da psicanálise freudiana, assim como os seus modelos tomados das ciências da natureza. Paul Ricoeur, por exemplo, no seu livro De l'interprétation, mostra como o freudismo apoia-se numa indefinição epistemológica: uma tensão constante entre energética e hermenêutica. Eis aqui a verdadeira aporia apresentada pela Deutung freudiana, convocando alternativamente uma explicação de conflito de forças e uma exegese do sentido aparente através do sentido latente: o freudismo consiste precisamente em recusar esta alternativa (RICOEUR, 1965). Ao contrário, a fenomenologia reforça esse divórcio epistemológico opondo a cientificidade das ciências da natureza àquela das ciências do espírito, um divórcio reivindicado por Husserl, Heidegger, e ainda mais por Merleau-Ponty.

- O terceiro nível desta difícil comparação é a clínica: a definição freudiana da psicanálise torna indissociáveis a pesquisa, a prática

2 FREUD, Psychanalyse et "théorie de la libido" (apud FREUD, 1921-1938, p. 51). Sendo este texto escrito na França, infelizmente, pude aceder só a poucas versões em português dos textos mencionados aqui em francês. Por esta razão, as traduções em português são sempre minhas, salvo as dos textos de Freud, que provêm todas da Edição electronica brasileira das obras completas de Freud (FREUD, 1969-1980). 
clínica e a teorização. O inconsciente freudiano é possibilitado pela técnica e a clínica psicanalítica, dimensões que nenhuma fenomenologia pode abastecer. My mistress eyes are nothing like the sun.

Porém, Merleau-Ponty tentou várias vezes favorecer aproximações entre as duas disciplinas, acrescentando que "é por aquilo que insinua o que descobre no seu limite - pelo seu conteúdo latente ou inconsciente - que a fenomenologia está em consonância com a psicanálise: não são paralelas, mas dirigem-se ambas em direção da mesma latência" (MERLEAU-PONTY, 2000, p. 281).

"Conteúdo inconsciente" e "latência comum": o filósofo pede emprestado vocabulário psicanalítico para falar da sua área, mas pode fazê-lo só reconhecendo a distância irredutível entre as duas disciplinas. Nessa tentativa de comparação, escolho considerar a filosofia de Merleau-Ponty como uma fenomenologia não cognitiva, mas afetiva, uma fenomenologia que, como dizia Lacan na sua homenagem à Merleau-Ponty, "desborda do seu campo", para encontrar a psicanálise. Se a comparação é possível, é graças à travessia da fenomenologia que Merleau-Ponty realizou, para se abocar a uma psicanálise atravessada no outro sentido. Gostaria, após ter atravessado o desmentido de falsas comparações, tentar verificar se e como se pode realizar uma verdadeira aproximação entre a fenomenologia de Merleau-Ponty e a psicanálise freudiana, a respeito do tema do corpo.

\section{Falsas comparações?}

Mas primeiro é preciso desmentir as falsas comparações. My mistress eyes are nothing like the sun. Eis aqui as divergências a respeito da questão do corpo.

Várias críticas dirigidas por J-B. Pontalis, André Green, Jacques Lacan ou Cornelius Castoriadis à fenomenologia de Merleau-Ponty concernem à sua tematização do corpo. Mesmo se o fenomenólogo escolhe uma via diferente da filosofia da consciência, realçando o corpo mais do que a consciência, falha em apanhar o inconsciente freudiano quando o reduz ao implícito, ao ambíguo ou ao sobredeterminado. Uma filosofia da percepção, dando a primazia ao corpo perceptivo, não pode integrar a teoria freudiana sem desnaturizá-la (PONTALIS, 1993, p. 76-97). 
Segundo A. Green (1964), o corpo é sobretudo libidinal para Freud, enquanto para Merleau-Ponty não é primeiramente libidinal, o que termina por afetar a sua concepção do inconsciente. Se Merleau-Ponty concede uma prioridade à percepção, a psicanálise segundo Green (1999), funda-se na noção de estrutura, para a qual a significância vale mais do que o sentido perceptivo.

Lacan faz uma crítica ainda mais severa quando denuncia a ausência da dimensão simbólica na obra do filósofo. Ao se aferrar a uma concepção do corpo como lugar de unidade, a fenomenologia limita-se a um mero plano imaginário.

Finalmente, Castoriadis (1997), o quarto psicanalista lendo MerleauPonty, repreende também a primazia que o filósofo concede à percepção: o fenomenólogo desconsidera a imaginação radical da qual procede, segundo Castoriadis, toda percepção e toda imaginação.

Essas quatro críticas endereçam-se à concepção do corpo desenvolvida por Merleau-Ponty, uma concepção que provoca na sua fenomenologia uma negligência da divergência central de regime entre a consciência e o inconsciente. Eis aqui a crítica principal em que concordam os psicanalistas: na sua teorização do inconsciente diretamente fundamentada sobre a impessoalidade do corpo próprio, Merleau-Ponty estabelece uma continuidade, uma indivisão entre a consciência e o inconsciente. Esta postura é diametralmente oposta ao corte, à ruptura e à barra instituída pela psicanálise entre os dois sistemas. My mistress eyes are nothing like the sun. Merleau-Ponty falha, segundo esses psicanalistas, em compreender a especificidade do inconsciente psicanalítico, definido precisamente pela sua separação radical da consciência.

Embora a crítica da indivisão seja perfeitamente justificada com relação às representações do inconsciente - psicanalítico -, ela, todavia, não se aplica à categoria do afeto, cujo estatuto é ao mesmo tempo consciente e inconsciente. Nem verdadeiramente consciente, por ter sido inibido no seu desenvolvimento, nem completamente inconsciente, porque existe somente num estado "rudimentar" no sistema inconsciente, oscilando entre um sentir e uma quantidade - a energia do "quantum de afeto" - o afeto estabelece uma constante transição entre o soma e a psique, uma comunicação além da separação radical entre eles. O afeto é, como escrevia André Green, "um olhar sobre o corpo emocionado" (GREEN, 1973, p. 221): envolve uma autopercepção do corpo acompanhando a percepção, a imaginação, o sono ou a lembrança que desprendeu este afeto. Surgindo do corpo, ao ser o representante o mais corporal da pulsão, o afeto é frequentemente um sentimento cujo sentido perdeu-se e que retorna no corpo, como quando estala uma crise de lágrimas, rebenta uma 
gargalhada ou paralisa os membros de angústia. O afeto acompanha-se então de um elemento de surpresa que torna estrangeira uma parte do meu corpo, escapando à minha consciência. Há muitos pontos da teorização de MerleauPonty que concordam com este autoescapamento do afeto.

\section{Afeto e fenomenologia do corpo}

\section{Corpo impessoal e pré-consciente}

Ao longo de toda a sua obra, Merleau-Ponty teoriza uma dimensão de impessoalização do corpo, que institui uma leitura do corpo escapando ao mesmo tempo à perspectiva objetivadora da ciência reducionista e à perspectiva reflexiva de uma filosofia da consciência. Na Estrutura do comportamento, o organismo revela uma estruturação específica, e não se reduz nem a um mosaico de estímulos físicos dispersos, nem à consciência de si. A sua impessoalização é uma terceira via entre o modo da coisa, a sustância estendida cartesiana, e o modo da consciência, a sustância pensante: manifesta-se, na Fenomenologia da percepção, em fenômenos normais ou patológicos, como o sono, o sonho, o membro fantasma ou a anosognosia.

Do mesmo modo, Merleau-Ponty opõe-se tanto ao corpo-máquina do naturalismo, um exterior sem interior, como à posição de sujeito constituinte universal na filosofia do sujeito, um interior sem exterior. As posições afetivas e práticas do sujeito não são nem um mecanismo físico-psicológico nem uma reflexividade transparente: implicam o sujeito susceptível de impessoalização, que é o meu corpo, engajado num mundo inter-humano, não pela intencionalidade de ato husserliana, mas por uma intencionalidade operante ${ }^{3}$ (fungierende intentionalität). Esta intencionalidade é antepredicativa: antes de qualquer definição do objeto vivido, do objeto da ciência ou do objeto transcendental, ela unifica o mundo e a vida do sujeito (MERLEAU-PONTY, 1945, p. xiii). Trata-se de uma atividade sucedendo sem tematização, sem atenção imanente, nem reflexão explícita. Eis aqui a operatividade da experiência corporal: o corpo vivido é principalmente habitado sem que a sua percepção, os seus movimentos ou a sua emoção sejam retomados pela reflexão. A intencionalidade operante, portanto, amplia a intencionalidade do ato, propriedade de uma consciência constituinte ao corpo inteiro: a nossa relação

3 MERLEAU-PONTY, 1945, p. 92. 
com o mundo, antes de ser predicativa, é carnal e corporal. Ela consiste numa ligadura inabalável entre a percepção exterior e uma realidade psíquica afetiva. Esta falta de reflexão ou tematização das atividades do corpo é contígua de uma falta de saber, de um afastamento da consciência: trata-se aqui já de um pré-consciente. Esta impessoalização do corpo corresponde, em nossa leitura, a uma excentricidade do afeto, concebido como uma coloração consciente errada, de sentido escapado, e carreando um infigurável inconsciente. O corpo é, por conseguinte, descrito como "aquele fundo afetivo que deita originariamente a consciência fora de si-mesma” (MERLEAU-PONTY, 1945, p. 110).

Essa legivelidade, diretamente sobre o corpo, do afeto em busca de sentido, induz uma transmissão entre soma e psique, além do dualismo clássico entre alma e corpo. De fato, a concepção merleau-pontyana do corpo refuta esse dualismo.

\section{Dualismos metafísicos}

A dicotomia errada do corpo e da alma pode servir como paradigma de todas as oposições que Merleau-Ponty questiona na Fenomenologia da percepção: a do objeto e do sujeito, a do mundo e da consciência, a do em-si e do por-si, ou a do sentido e do signo. ${ }^{4}$ Já desde a Fenomenologia da percepção, e até $O$ Visível e o invisível, trata-se para Merleau-Ponty de adentrar-se "nessa dimensão de composto de alma e corpo, de mundo existindo e de Ser abissal que Descartes abriu e imediatamente fechou" (MERLEAU-PONTY, 1960c, p. 58-60). Para superar a alternativa entre físico e psíquico, alma e corpo, interior e exterior, sujeito da percepção e objeto percebido, Merleau-Ponty articula o corpo, a psique e um terceiro termo entre o psíquico e o fisiológico: a existência.

O corpo pensado por muitos psicanalistas coloca-se também além do dualismo cartesiano, apesar da ontologia dualista clássica herdada pelo primeiro Freud. Pierre Fédida recorda como a apreensão do corpo pela psicanálise inscreve-se contra a perspectiva cartesiana de uma anatomia objetivadora ou de qualquer dualismo (FÉDIDA, 1977). De fato, a anatomia corresponde a uma concepção naturalizadora do corpo que desleixa a sua importante dimensão fantasmática, mais primordial, pelo corpo de um sujeito, do que qualquer nível científico. Similarmente, para Merleau-Ponty, o saber da anatomia

${ }^{4}$ VILLELA-PETIT, 1988.

Rev. Filos., Aurora, Curitiba, v. 22, n. 31, p. 495-513, jul./dez. 2010 
positiva é um artefato: trata-se de uma construção segunda, ocorrendo só depois da percepção pré-objetiva do corpo.

\section{Modelos do sentido}

Há um outro dualismo que Merleau-Ponty Merleau-Ponty (1945, p. 176) recusa, paralelamente a todos os dualismos errados: é a separação da linguagem e do pensamento. Mais uma vez, o corpo é central aqui. Já desde a Fenomenologia da percepção, Merleau-Ponty compara o corpo à uma obra de arte: nele acontece a mesma fusão entre expressão e exprimido, característica da obra de arte.

Um romance, um poema, um quadro, ou uma peça de música, escreve Merleau-Ponty, são indivíduos, é dizer seres onde não se pode distinguir a expressão do exprimido, cujo sentido é acessível só por contato direito e que irradiam a sua significação sem deixar a sua colocação temporal e espacial. O nosso corpo é comparável à obra de arte neste sentido. E um nodo de significações vivas.

Esta expressividade do corpo é "uma operação primordial de significação, onde o exprimido não existe à parte da expressão, e onde os signos mesmos induzem o seu sentido para o exterior" (MERLEAU-PONTY, 1945, p. 193). O corpo é a sede desta expressividade através da sua intersensorialidade: nele realiza-se a unidade das experiências visuais, auditivas, tácteis e da comunicação entre elas.

O valor expressivo destas experiências reunidas fundamenta primeiro a unidade antepredicativa do mundo percebido, e logo a expressão verbal e a significação intelectual (MERLEAU-PONTY, 1945, p. 271-272) - porque a linguagem mesma é concebida como uma continuação do gesto corporal na sua relação com o mundo sensível. A articulação linguística é, portanto, uma conduta do corpo conferindo uma significação ao mundo enquanto o exprime. Eis aqui, na fenomenologia de Merleau-Ponty, uma verdadeira continuidade entre a linguagem e os fenômenos pré ou a-linguísticos, como se se tratasse de níveis diferentes de uma única operação expressiva. Isso é a base da confusão entre estrutura e significação que lhe repreendem os psicanalistas.

Os modelos de concepção do sentido são, de fato, diferentes entre a fenomenologia e a psicanálise. Ambas, certamente, opõem-se ao modelo 
da referência exterior: ainda mais do que Husserl, Merleau-Ponty recusa a ideia de uma consciência representativa em que o sentido se formaria pela referência de uma representação interna a um objeto externo. Similarmente, na psicanálise, o sentido não consiste na referência de um símbolo a um simbolizado, numa estrita equivalência bijetiva. Todavia, há uma grande diferença entre o modelo da expressão de um lado - em que o sentido jaz na fusão do exprimido e da expressão - e o modelo estrutural do outro lado - no qual o sentido é diacrítico, e se forma por um processo de de-diferenciação e oposição interna entre os elementos. Esta divergência é que opõe o sentido encarnado, característico da fenomenologia, e a significância, própria do modo de funcionamento do inconsciente. Esta disparidade é que fundamenta também a distinção entre as concepções do corpo da fenomenologia e da psicanálise.

Essa dissimilitude aparece claramente se compararmos a expressividade do corpo tematizada por Merleau-Ponty e a do fenômeno histérico, tal como Freud descreveu desde o início da teorização. A dor histérica tem um estatuto singular: é um elemento material provindo de uma verdadeira linguagem do corpo, mas que traz em si, simbolicamente, outra lógica psíquica. Eis aqui uma passagem da análise de Fraülein Von R., na qual Freud (1895, p. 108) usa o termo de expressão:

No caso da Srta. von R., contudo, quando se pressionava ou beliscava a pele e os músculos hiperalgésicos de suas pernas, seu rosto assumia uma expressão peculiar, que era antes de prazer do que de dor. Ela gritava mais e eu não podia deixar de pensar que era como se ela estivesse tendo uma voluptuosa sensação de cócega - o rosto enrubescia, ela jogava a cabeça para trás e fechava os olhos, e seu corpo se dobrava para trás.

O corpo é expressivo aqui numa sedimentação: as dores das duas coxas, a abasia e astasia de que padece Elisabeth relatam o conflito entre o impulso amoroso que ela sente para um jovem com quem quer ficar numa festa, e a necessidade de se ocupar do seu pai doente, ou este outro conflito entre o desejo inaceitável que ela sente para o seu cunhado e os imperativos de conveniência moral e social. O sintoma histérico, compromisso entre o desejo e a defesa, oferece um modo desviado de realizar o desejo: a "expressão de satisfação" é outra camada dessa expressividade do corpo. Na dor histérica, a representação é recalcada e o afeto convertido: este afeto retornado no corpo ao ser transformado em dor, abasia ou astasia - traz a sedimentação de um 
afeto de desejo por um homem, da interdição moral oposta, e da satisfação final achada no sintoma. O corpo é expressão e exprimido.

Contudo, o sintoma histérico inscreve-se só sobre um corpo já investido pela linguagem. Se Elisabeth, no seu processo de lembrança, junta e une as cenas do passado, segundo a posição ocupada por seu corpo, é essencialmente, também, segundo uma comunidade de imagens verbais: ela é literalmente "cravada no lugar" quando, em pé, assiste ao retorno à casa do seu pai, levado por homens porque acaba de ter uma crise cardíaca, ou, similarmente, quando, outra vez em pé, permanece fitada diante do leito de morte da sua irmã. Do mesmo modo, a sua astasia-abasia refere-se ao seu doloroso sentimento de solidão (o tradutor do texto alemão recorda que a expressão alemã para solidão diz literalmente "ficar em pé sozinho") ou à sua impressão de não "poder avançar". ${ }^{5}$ Nesse sentido, a continuidade entre corpo e linguagem apontada pela fenomenologia é invertida: não é o corpo que induz a linguagem a partir da sua expressividade, determinando a palavra como continuação do gesto, mas, pelo contrário, a linguagem precede o corpo, vivido e sentido a partir de certas "representações de palavras".

Este aspecto é bem comentado por Monique David-Ménard em seu livro L'Hystérique entre Freud et Lacan. As posições de Elisabeth referem-se à outra cena, um espaço de gozo imaginário transformando o seu corpo num lugar mágico onde tudo ocorre para ela, mas sem ela. Esse gozo é inscrito numa relação com a linguagem, precedendo qualquer percepção. De fato, o sujeito pode perceber o corpo próprio só a partir de certo tipo de simbolização: "a percepção não é nunca primeira nem independente da história de um gozo que se significa nela" (DAVID-MÉNARD, 1983, p. 50). Na histeria, o corpo figura zonas de desejo e de gozo sobre a sua superfície: interpreta-se ele mesmo, e reinterpreta a linguagem fabricando um sintoma que concede uma dimensão carnal à linguagem.

Diferentemente, na Fenomenologia da percepção, o fenômeno da linguagem é induzido pelo campo fenomenal da percepção, um campo que escapa a uma tematização total: a linguagem é fundamentada sobre a encarnação, que lhe dá todo o sentido. A direção da fundamentação é exatamente oposta na conceituação psicanalítica: o corpo é que se assenta sobre a linguagem. Esta diferença e a falta de distinção entre corpo e linguagem são reprovadas ao filósofo pelos psicanalistas.

5 FREUD, 1895, p. 121. 
Face a isso, aparece uma diferença categórica entre o corpo próprio da fenomenologia, primeiramente perceptivo, e corpo de linguagem da psicanálise, primordialmente simbólico e não fenomenal, resultando de um processo de significância estrutural, e não de sentido expressivo. Aqui jaz a disparidade principal entre o corpo fenomenal e o corpo fantasmático.

\section{O corpo fantasmático: além da fenomenologia}

\section{Antecedência do fantasma}

A especificidade da perspectiva psicanalítica, diferenciando-a de qualquer descrição fenomenológica, é a de referir-se a uma dimensão fantasmática irredutível, jazendo embaixo de toda apreensão do corpo.

O princípio de prazer-desprazer é fundamental na autossensação do corpo: na psicanálise freudiana, este princípio faz do corpo a sede do afeto. Eis aqui uma vivência do corpo muito diferente daquela descrita pela fenomenologia: nessa vivência, os atos psíquicos da percepção e da imaginação são indissociáveis. De fato, na teoria freudiana (FREUD, 1923), o Ego é de origem corporal: é um efeito físico produzido na superfície do corpo. Freud coloca o Ego na superfície do Id inconsciente: é a sua parte modificada pela influência direta do mundo exterior, por meio do sistema percepção-consciência (FREUD, 1923, p. 237). Na separação entre o Ego e o Id, o corpo próprio, superfície de transição das percepções externas e internas, joga um rol central. O Ego é assim a projeção mental da superfície do corpo, ele resulta das sensações corporais provindo desta superfície (FREUD, 1923, p. 238). Quando o ego tenta designar o corpo, cai num jogo de espelhos, numa série de aparências reforçando a ideologia de um poder do Ego. Ao entrar no campo do pensamento consciente, o corpo induz uma ilusão "intra-projetiva" (FÉDIDA, 1977, p. 69): como nota Pierre Fédida, as noções de "consciência do corpo próprio", "experiência do corpo", "esquema corporal" ou "imagem do corpo" são já alteradas por esta ilusão primária.

Daqui surge a falha, como realça Fédida, de todo discurso psicológico que tenta compreender o corpo. Para efetuar uma psicologia do corpo, distinta de uma psicologia da consciência do corpo e que não seja submetida a esta ilusão intraprojetiva, convém centrar-se só numa escuta do corpo portanto, convém voltar a passar pela linguagem. A única fenomenologia do corpo suscetível de torná-lo visível seria uma narrativa imaginária do corpo, 
um "poema do corpo" (FÉDIDA, 1977, p. 84), tal como no mito, no fantasma ou no sonho. Na sessão analítica, a única apreensão do corpo faz-se através deste espaço, "dando a escutar o visível” (FÉDIDA, 1977, p. 99). O destino do corpo é, logo, intimamente ligado àquele da linguagem expressando o corpo: fora desta linguagem, não há nenhum corpo real, mas só a ilusão imaginária de um corpo vivido.

Em vista disso, o corpo vivido apontado pela fenomenologia é somente, pela psicanálise, o artefato de uma formação fantasmática, do mesmo modo que o corpo objetivo das ciências da natureza era, para a fenomenologia, um artefato. Se a fenomenologia opõe o Leib, corpo vivido e subjetivo, ao Korper, corpo da ciência, da anatomia, do cálculo e da objetividade aprendido desde o exterior, a psicanálise acrescenta uma nova distinção: o Leib opõe-se ao corpo libidinal, fantasmático. Para a psicanálise, a anatomia, assim como a geografia fenomenal do corpo vivido, são igualmente fantasmáticas.

\section{Percepção e imaginação}

Essa divergência entre um corpo primordialmente fantasmático pela psicanálise e um corpo primariamente perceptivo pela fenomenologia pode ser explicada pela análise desenvolvida por Freud no texto "A negativa". ${ }^{6}$ Para Freud, a percepção é sempre segunda: acontece em dois tempos, após o princípio de realidade ser estabelecido. Pelo sujeito começando a perceber o mundo, institui-se primeiro um julgamento de atribuição: define-se um atributo, bom ou mau, útil ou prejudicial, e o julgamento é 'gostaria de botar isso para dentro de mim e manter aquilo fora'. Portanto, o Ego introjeta o bom e projeta fora o mau, segundo uma repartição afetal ${ }^{7}$ regida pelo principio de prazerdesprazer. O Ego assim formado é um Ego-prazer, para quem percepção e imaginação são confundidas. A partir desse Ego-prazer inicial desenvolve-se um Ego-realidade, usando o julgamento de existência para verificar que existe no real o que foi instituído na representação.

Agora, escreve Freud, não se trata mais de uma questão de saber se aquilo que foi percebido (uma coisa) será ou não integrado ao ego, mas uma questão

6 “A negativa", em Freud (1921-1938).

7 Use este termo aqui, em vez do termo "afetivo", para referir-me ao afeto no sentido psicanalítico, e não à afetividade. 
de saber se algo que está no ego como representação pode ser redescoberto também na percepção (realidade). ${ }^{8}$

A percepção sucede então num primeiro tempo - momento do julgamento de atribuição - e induz uma representação do bom interior e do mau exterior; num segundo tempo, o teste de realidade vem verificar e controlar que esta repartição fantasmática corresponde ou não ao real: "Portanto, conclui Freud, o objetivo primeiro e imediato do teste de realidade é não encontrar na percepção real um objeto que corresponda ao representado, mas reencontrar tal objeto, convencer-se de que ele está lá". ${ }^{9}$

Por conseguinte, quando ocorre o segundo tempo da percepção, estabelece-se sobre um fundo fantasmático: o mundo então percebido e as zonas reveladas tinham sido primeiramente estruturados e construídos pelo prazer e o desprazer.

A leitura deste texto por Lacan, na "Resposta ao comentário de Jean Hyppolite sobre a Verneinung de Freud" (LACAN, 1966, p. 381-399), liga à linguagem esta ontologia freudiana da percepção primeiramente fantasmática. Lacan evoca a contrario a análise da alucinação do dedo cortado do Homem dos lobos, para apontar a estruturação simbólica de toda realidade perceptiva, desenvolvendo as suas três categorias de Imaginario, Simbólico e Real. O Homem dos lobos tem acesso "intelectual" à realidade genital, mas ele mantém o processo de "negativa" descrito por Freud (aceitação intelectual e recuso afetivo) e manifesta uma fixação a uma teoria sexual da fase anal. A sua posição feminina na captação imaginária do traumatismo primordial (a cena primitiva do coito a tergo dos pais) impede que assuma a realidade genital sem se sentir ameaçado pela castração. A ideia de castração é aqui rejeitada, não por recalcamento (Verdrängung), mas por forclusão (Verwerfung), induzindo uma anulação simbólica.

Para Lacan, a Verwerfung é exatamente oposta ao julgamento de atribuição primário: a Verwerfung impede qualquer manifestação da ordem simbólica, qualquer repartição fantasmática do interior e do exterior, do bom e do mau. O que não pode ser percebido por causa da Verwerfung desaparece da história do sujeito, porque não acedeu ao nível simbólico. Eis aqui o que Lacan chama de Real: o que subsiste fora da simbolização. Quando o Real emerge, provoca uma alucinação, aparição na realidade do que não existe pelo sujeito, o

8 “A negativa”, em Freud (1921-1938, p. 137).

9 “A negativa”, em Freud (1921-1938, p. 138). 
que não foi simbolizado. A alucinação do dedo cortado em o Homem dos lobos é uma volta do Real, do que não foi simbolizado, do que ficou fora, porque o rapaz manteve no seu inconsciente uma posição feminina anulando a castração.

Face a isso, é preciso asseverar uma divergência completa no uso terminológico da fenomenologia e da psicanálise. A percepção da fenomenologia é, pela psicanálise, uma percepção segunda: ela é a confirmação de uma representação imaginária construída sobre uma seleção, um filtro do percebido por meio do prazer-desprazer, introduzindo o bom e expulsando o mau. Portanto, a alucinação é, pela psicanálise, aquela "percepção primeira" diferida: ela é a reemergência daquilo que não foi percebido e simbolizado uma primeira vez.

Para a fenomenologia, a alucinação procede de uma intencionalidade imaginária: ela é ligada à imaginação. Para a psicanálise, é só uma percepção diferida, nua, não simbolizada: ela não é imaginária (no sentido lacaniano), mas impede a formação do imaginário (o campo perceptivo, pela fenomenologia), e aplana o Real sobre o Simbólico. Ao contrário, para a psicanálise, a percepção é que é imaginária, no sentido que se desenvolve a partir de uma construção fantasmática surgida de uma primeira filtragem pelo afeto. Em vista disso, parece legítimo dizer que o corpo é o lugar exclusivo do imaginário, como fazem os psicanalistas. Todavia, esta alegação implica uma inversão total dos termos real/imaginário, da fenomenologia à psicanálise.

Contudo, não nos encontramos, nessa modelização psicanalítica, de novo confrontados com uma ontologia dualista?

\section{Reescrevendo uma ontologia dualista?}

Examinemos de novo o texto "A negativa". O julgamento de atribuição consiste, mais que em atribuir qualidades a objetos identificados como exteriores, em admiti-los dentro de si. ${ }^{10}$ Eis aqui certas contradições: a indistinção entre Ego e não-Ego não é originária, mas constrói-se sobre este julgamento de atribuição que incorpora os bons objetos e rejeita os maus. Neste mito heurístico freudiano da instituição da percepção, a distinção clássica dentro/fora, sujeito/objeto não é requisitada; todavia, ela aparece aqui como fundamento dessa indistinção entre Ego e não-Ego (a qual, como vimos, provém, segundamente, do julgamento de atribuição). Não cabe dúvida que Freud questiona a dualidade sujeito/objeto de onde procede a ontologia

10 “A negativa”, em Freud (1921-1938, p. 137).

Rev. Filos., Aurora, Curitiba, v. 22, n. 31, p. 495-513, jul./dez. 2010 
clássica (por exemplo, introduzindo o objeto interno). Porém, se há de admitir que a possibilidade de incluir ou excluir depende do reconhecimento de tal dualidade: para que o Ego-prazer introjete o bom e projete o mau, ele tem que ser ao princípio distinto do que introjeta ou projeta. Para Monique Schneider, o postulado implícito perpetuado pelo pensamento freudiano aqui consiste em "ter por adquirido que, anteriormente a qualquer avaliação predicativa, anteriormente à alternativa pulsional da engolição ou da cuspida, uma cousa (Ding) seja dada" (SCHNEIDER, 1988).

Aliás, como um Ego pode ser distinto do não-Ego, enquanto, conforme postula Freud várias vezes - em "Sobre o narcisismo: uma introdução" ou em "Os instintos e as suas vicissitudes" - o Ego não é primeiro, mas é construído? Freud está, pelo visto, perpetuando aqui uma ontologia dualista de interior/exterior, sujeito/objeto, ao passo que o mito heurístico dos inícios da vida psíquica pretende contravir a esta ontologia.

Cabe ressaltar aqui de novo que Merleau-Ponty tenta definir a sua fenomenologia além da dualidade sujeito/objeto, Ego/não-Ego, dualidade ao mesmo tempo refutada por Freud e convocada pela sua teorização da negativa. Já no princípio da sua obra, o filósofo distingue as relações entre soma e psique de toda relação entre sujeito e objeto, porque a experiência do corpo e a intencionalidade operante no seu fundamento se opõem ao movimento reflexivo que ergue sujeito e objeto como duas entidades distintas.

Mais claramente aparece esta refutação da ontologia dualista do sujeito/objeto no modelo da carne, desenvolvido no Visivel e o invisivel. A carne faz aparecer uma antecedência do mundo onde sempre estou localizado: distingo-me do mundo precisamente à medida que ele me inclui. A carne dá conta de uma dimensão que precede a dualidade sujeito/objeto, mas que a institui, à medida que surgem não o sujeito e o objeto, mas o sentinte e o sensível. A reversão da carne teorizada por Merleau-Ponty - de tocado em tocante, de visível em vidente, de percebido em percebente - é o que me vincula, como sensível, a tudo o sensível, e me separa dele como sentinte. Vidente e visível, tocante e tangível, o meu corpo é um "ser de duas camadas". Nesse sentido, ele não precisa sair dele mesmo nessa transcendência que o liga ao mundo: ele é somente a referência de um visível a todos os visíveis, de um tangível a todos os tangíveis. Este modelo da carne parece permitir teorizar a separação/indivisão a partir do sentinte/sensível, e também conceber um sentinte ainda não constituído como unidade - ou seja, em termos analíticos, como Ego organizado.

Um primeiro vínculo afetal e afetivo esboça, por meio do filtro do prazer-desprazer, entre o recém-nascido e o seu entorno, um mundo ao mesmo 
tempo distinto do Ego construidor e prolongando-o. O mundo é presente à minha carne através da sua carne, eu formo parte dele, mas não sou ele (MERLEAU-PONTY, 1960c, p. 169): eis aqui fórmulas merleau-pontyanas que permitem dar conta da genealogia fantasmático-perceptiva do mundo para o recém-nascido, e da continuidade-descontinuidade entre eles.

\section{Conclusão}

Por um lado, o corpo próprio, Leib, da fenomenologia, parece condenado a permanecer considerado como uma captação imaginária, nos termos da metapsicologia. Por outro, o modelo metapsicológico apresenta, porém, a aporia de proceder de uma ontologia dualista clássica, e admite uma redefinição por via da filosofia da carne merleau-pontyana.

Em outros termos, a abordagem psicanalítica do corpo aponta a insuficiência, ou pelo menos a parcialidade imaginária de qualquer tematização do corpo pela fenomenologia: revela o corpo próprio como mero efeito de um corpo primordialmente fantasmático e considera a percepção, originária pela fenomenologia husserliana, como um momento segundo ocorrendo após uma primeira camada fantasmática arcaica. A psicanálise permitiria, então, prolongar uma pesquisa fenomenológica além dos limites da atestação. Todavia, a partir do conceito de carne, a fenomenologia pode retificar a ontologia dualista do modelo metapsicológico, oferecendo uma modelização que resolve esta aporia.

Lembremos, porém, que as noções - percepção, imaginação ou carne - não valem da mesma forma na fenomenologia e na psicanálise. Freud avisa várias vezes do seu uso metafórico ou só por esboços da língua da teorização, em que não se deve "tomar o andaime pelo edifício mesmo". Nesse sentido, o valor teórico da psicanálise não é comparável ao de outras teorias, e a psicanálise não é só uma nova teoria que se acrescenta às outras. Trata-se na realidade operações de busca ligando, como começamos por dizer, a pesquisa, o tratamento e o corpo de conhecimentos. Portanto, é preciso não fixar a teoria em nenhuma doutrina, e deixá-la aberta à interação com outras disciplinas.

Consciente, talvez mais do que as outras disciplinas, da dimensão plenamente afetiva da sua teorização, a metapsicologia não usa conceitos filosóficos. Ela reintroduz a atividade metafórica dentro do conceito: a noção de carne, que permite ultrapassar a ontologia dualista da teorização freudiana, funciona como conceito na fenomenologia de Merleau-Ponty. Porém, ela vale só como metáfora na metapsicologia. A metapsicologia caracteriza-se, logo, 
pela sua função mitogenética, em que a metáfora substitui o poder de operatividade técnico do conceito.

Se é graças a um desmentido das falsas comparações que se pode estabelecer uma aproximação entre psicanálise e fenomenologia, é também por via de um luto central: o luto de uma operatividade conceitual que seja a mesma para ambas.

My mistress' eyes are nothing like the sun.

Deixemos as últimas palavras a Shakespeare, que, num outro soneto, ligava a comparação a um luto:

My mistress' eyes are raven black, Her eyes so suited, and they mourners seem At such who, not born fair, no beauty lack, Sland'ring creation with a false esteem. ${ }^{11}$

\section{Referências}

DAVID-MENARD, M. L'Hystérique entre Freud et Lacan. Corps et langage en psychanalyse. Paris: Editions Universitaires Les jeux de l'inconscient, 1983.

CASTORIADIS, C. Merleau-Ponty et le poids de l'héritage ontologique. Fait et à faire. Paris: Seuil, 1997. p. 157-194.

FÉDIDA, P. Corps du vide et espace de séance. Paris: Jean-Pierre Delarge, 1977.

FREUD, S. Essais de psychanalyse. Tradução de sous la direction de Jean Laplanche. Paris: Payot, 1982. Publicado originalmente em 1915-1923.

FREUD, S. Résultats, idées, problèmes II. Paris: PUF, 1985. Publicado originalmente em 1921-1938.

FREUD S. Standard Edition das obras completas de Sigmund Freud. Rio de Janeiro: Imago, 1969-1980. 1 CD-ROM.

11 "Os olhos da minha amante são pretos como o corvo

E pretas a suas celhas, que parecem estar de luto

por aqueles não loiros desprendendo beleza

como se acusassem a criação do seu engano".

Tradução livre do autor. 
GREEN, A. Du comportement à la chair: itinéraire de Merleau-Ponty. Critique, n. 211, p. 1017-1046, 1964.

GREEN, A. Le Discours vivant. Paris: PUF, 1973.

GREEN, A. Sur la discrimination et l'indiscrimination affect-représentation. Revue Française de Psychanalyse, Tome 63, n. 1, p. 217-271, 1999.

LACAN, J. Ecrits. Paris: Seuil, 1966.

MERLEAU-PONTY, M. La Structure du comportement. Paris: PUF, 1942.

MERLEAU-PONTY, M. Phénoménologie de la perception. Paris: Gallimard, 1945.

MERLEAU-PONTY, M. Préface à L'CEuvre de Freud, A. Hesnard. Paris: Payot, 1960a.

MERLEAU-PONTY, M. Signes. Paris: Gallimard, $1960 \mathrm{~b}$.

MERLEAU-PONTY, M. Le Visible et l'invisible. Paris: Gallimard, 1960c.

MERLEAU-PONTY, M. Parcours deux, 1951-1961. Paris: Verdier, 2000.

DA PENHA VILLELA-PETIT, M. Le Tissu du réel. Essai sur l'ontologie de MerleauPonty. In: COLETTE, J. et al. Maurice Merleau-Ponty, le psychique et le corporel. Paris: Aubier, 1988. p. 89-114.

PONTALIS J.-B. Présence, entre les signes, absences. L'Arc, Merleau-Ponty, p. 56-66, 1971.

PONTALIS J.-B. La Position du problème de l'inconscient chez Merleau-Ponty. In: PONTALIS J.-B. Après Freud. Paris: Gallimard, 1993. p. 76-97.

RICOEUR, P. De l'Interprétation: essai sur Freud. Paris: Seuil, 1965.

SHAKESPEARE, W. The ilustrated stratford Shakespeare. Londres: Chancellor Press, 1994. SCHNEIDER, M. Philosopher après Freud. In: ENCYCLOPEDIE PHILOSOPHIQUE UNIVERSELLE. L'Univers philosophique. Paris: PUF, 1998. Tome 1.

Recebido: $25 / 07 / 2010$

Received: 07/25/2010

Aprovado: 27/08/2010

Approved: 08/27/2010 